\title{
EVOLUÇÃO DAS PROPRIEDADES DE UM AÇO 27MnCrB5- 2 TEMPERADO COM DIFERENTES PARAMETROS DE TRATAMENTO TÉRMICO*
}

Daniel Augusto Ferro ${ }^{1}$ Fabio Stagetti ${ }^{2}$

\section{Resumo}

O aço 27MnCrB5-2 tem sido muito utilizado para aplicação em facas, além de peças de boa resistência mecânica e resistência ao desgaste, alguns exemplos são verificados no ramo agrícola como faca para corte basal de colheitadeiras de cana, lâminas de roçadeira e helicoide para transporte de grãos. A indústria de beneficiamento de papel/papelão é outro segmento onde esse aço está presente, sendo usado para facas de corte e vinco. Com o objetivo de melhorar a conformabilidade da liga $27 \mathrm{MnCrB5}-2$ no estado temperado, de forma a atender o nível de conformação solicitado, principalmente na fabricação de facas de corte e vinco, foram processados quatro lotes com diferentes conceitos de tratamento térmico de têmpera (martêmpera e austêmpera) para posterior avaliação das estruturas e propriedades mecânicas, a fim de correlacioná-las com a conformabilidade da dobra em cada situação. Com os resultados encontrados e testes práticos realizados durante fabricação da faca de corte e vinco, foi possível constatar melhora significativa na microestrutura/propriedade mecânica/processamento da peça considerando sua conformabilidade com um dos parâmetros de austêmpera utilizados.

Palavras-chave: 27MnCrB5-2; Conformabilidade; Martêmpera; Austêmpera.

\section{PROPERTIES EVOLUTION OF 27MNCRB5-2 QUENCHED STEEL WITH DIFFERENTS HEAT TREATMENT PARAMETERS}

\section{Abstract}

Steel $27 \mathrm{MnCrB5}-2$ has been widely used for application in knives, and pieces of good mechanical strength and wear resistance, some examples are recorded in the agricultural industry as a knife of cane harvesters, blades used in lawn-mower and parts to transport seed, the processing industry of paper / paperboard is another segment where this steel is present being used for cutting and creasing knives. In order to improve the formability of the alloy $27 \mathrm{MnCrB} 5-2$ in the hardened state to meet the level of strain required particularly in the manufacture of cutting and creasing knives, four batches were processed with different concepts of heat treatment (austempering and quenching) for later evaluation of the structure and mechanical properties in order to correlate them with the bending formability in each parameters used. The results and practical tests achieved during manufacturing of cutting and creasing knives, showed significant improvement in the microstructure/mechanical property/part processing related to formability considering a particular austempering process used. Keywords: 27MnCrB5-2; Stampability; Quenching; Austempering.

1 Engenheiro Mecânico, Mestre em Engenharia Metalúrgica pela EPUSP, Engenheiro de Desenvolvimento de Produto da Brasmetal Waelzholz S/A, São Paulo, SP, Brasil; dferro@brasmetal.com.br.

2 Engenheiro Metalurgista, Mestre em Engenharia Metalúrgica pela EPUSP, Engenheiro de Desenvolvimento de Produto da Brasmetal Waelzholz S/A, São Paulo, SP, Brasil; fstagetti@brasmetal.com.br. 


\section{INTRODUÇÃO}

A liga 27MnCrB5-2 conforme DIN EN 10083-3:2006 é considerada um aço de baixa liga e vem cada vez mais se consolidando em aplicações que requerem boa resistência ao desgaste aliada a razoável conformabilidade.

De acordo com catálogo Brasmetal [1], aços de baixa liga são aços de composição química direcionada, com adição de elementos químicos em quantidades específicas, diferenciando-os dos elementos químicos normalmente utilizados nos aços comuns. A adição de elementos de liga tem o objetivo de promover mudanças nas propriedades físicas e mecânicas, potencializando o desempenho do material em funções peculiares. Entre as propriedades que podem ser alteradas com a adição de elementos de liga podemos destacar a resistência à fadiga, resistência à corrosão, resistência ao desgaste, temperabilidade, ductilidade e tenacidade.

Conforme site INDA (Instituto Nacional dos Distribuidores de Aço) [2] aço de baixa liga é o aço cuja soma dos elementos de liga não ultrapassa $5 \%$.

O consumo do aço $27 \mathrm{MnCrB5}-2$ tem aumentado de forma considerável e, por esse motivo, torna-se necessário relacionar seu processamento com as propriedades finais, de modo a se obter as características desejáveis para determinada aplicação. No presente trabalho, foram utilizadas diferentes temperaturas de austenitização em processo de martêmpera em linha contínua, onde as propriedades mecânicas e microestrutura dos lotes processados foram avaliadas. Também foi feito um comparativo com lote da mesma liga com processo de austêmpera.

Os lotes processados foram destinados à aplicação faca de corte e vinco onde adicionalmente foram avaliados os requisitos de dobra especificados.

\section{FACAS DE CORTE E VINCO}

Diversos são os tipos e geometrias de facas de corte e vinco, onde o atendimento a dobra isento de trincas é de suma importância. As facas são mostradas na figura abaixo:

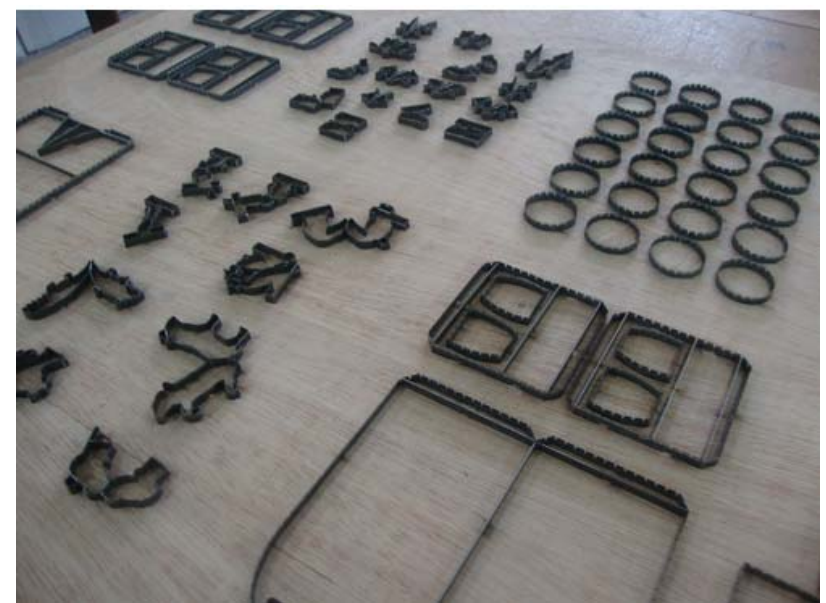

Figura 1: Exemplos de diferentes geometrias de facas para corte e vinco [3].

No tocante ao processo de fabricação das facas de corte e vinco, em geral usina-se a borda da tira de aço já no estado temperado de modo a formar o fio de corte, que é temperado por indução visando dureza de aproximadamente $50 \mathrm{HRC}$. Posteriormente a tira com a borda usinada é cortada e dobrada de acordo com a geometria do corte/vinco desejada. 
Para o item em estudo, é realizado um teste de dobra na tira temperada onde a mesma deve ser conformada, de acordo com a geometria da figura abaixo, sem apresentar trincas ou rupturas na região da dobra.

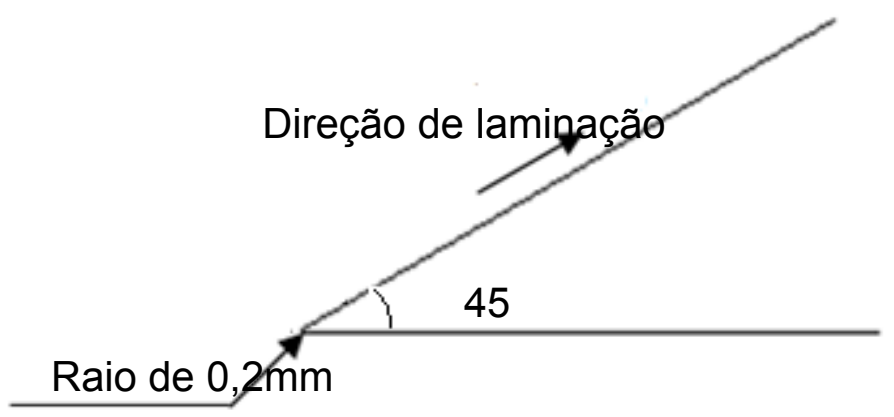

Figura 2: Ângulo e raio do teste de dobra (fonte: autor)

\section{COMPOSIÇÃO QUÍMICA DA LIGA $27 \mathrm{MnCrB5}$}

A tabela 1 apresenta a composição química especificada para a liga $27 \mathrm{MnCrB5}-2$ conforme norma DIN EN 10083-3:2006. [4]

Tabela 1: Composição química especificada para a liga 27MnCrB5-2 [4]

\begin{tabular}{|c|c|c|c|c|c|c|c|}
\cline { 2 - 7 } \multicolumn{1}{c|}{} & $\mathbf{C ~ ( \% )}$ & $\mathbf{S i}(\%)$ & $\mathbf{M n}(\%)$ & $\mathbf{P ~ ( \% )}$ & $\mathbf{S ~ ( \% )}$ & $\mathbf{C r}(\%)$ & $\mathbf{B ~ ( \% )}$ \\
\hline & 0,24 a & 0,40 & 1,10 a & 0,025 & 0,035 & 0,30 a & 0,0008 a \\
27MnCrB5 & 0,30 & máx. & 1,40 & máx. & máx. & 0,60 & 0,005 \\
\hline
\end{tabular}

\section{TEMPERABILIDADE DA LIGA 27MnCrB5}

Com a composição química especificada é possível se obter durezas máximas entre 47 e 55 HRC dependendo das dimensões da peça conforme mostra o gráfico levantado através do ensaio Jominy [4].

A dureza especificada pelas empresas produtoras de facas de corte e vinco em geral variam de 32 a 50 HRC dependendo do tipo de faca e conformação necessária para sua fabricação. O estudo foi realizado com um item de especificação de dureza entre 32 e 36 HRC.

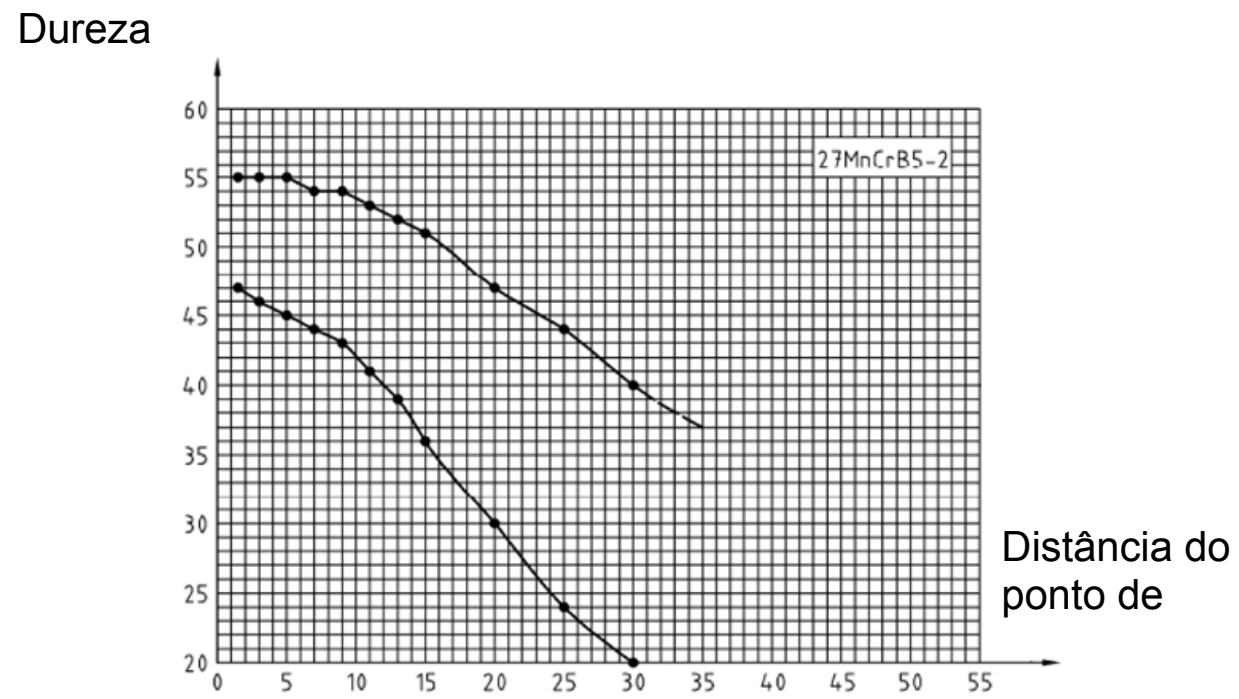

Figura 3: Perfil de dureza em ensaio Jominy realizado na liga 27MnCrB5-2 [4] 
A curva TTT do aço 27MnCrB5-2 está exemplificada abaixo e foi obtida pelo programa Stecal 3.0 para uma determinada composição química.

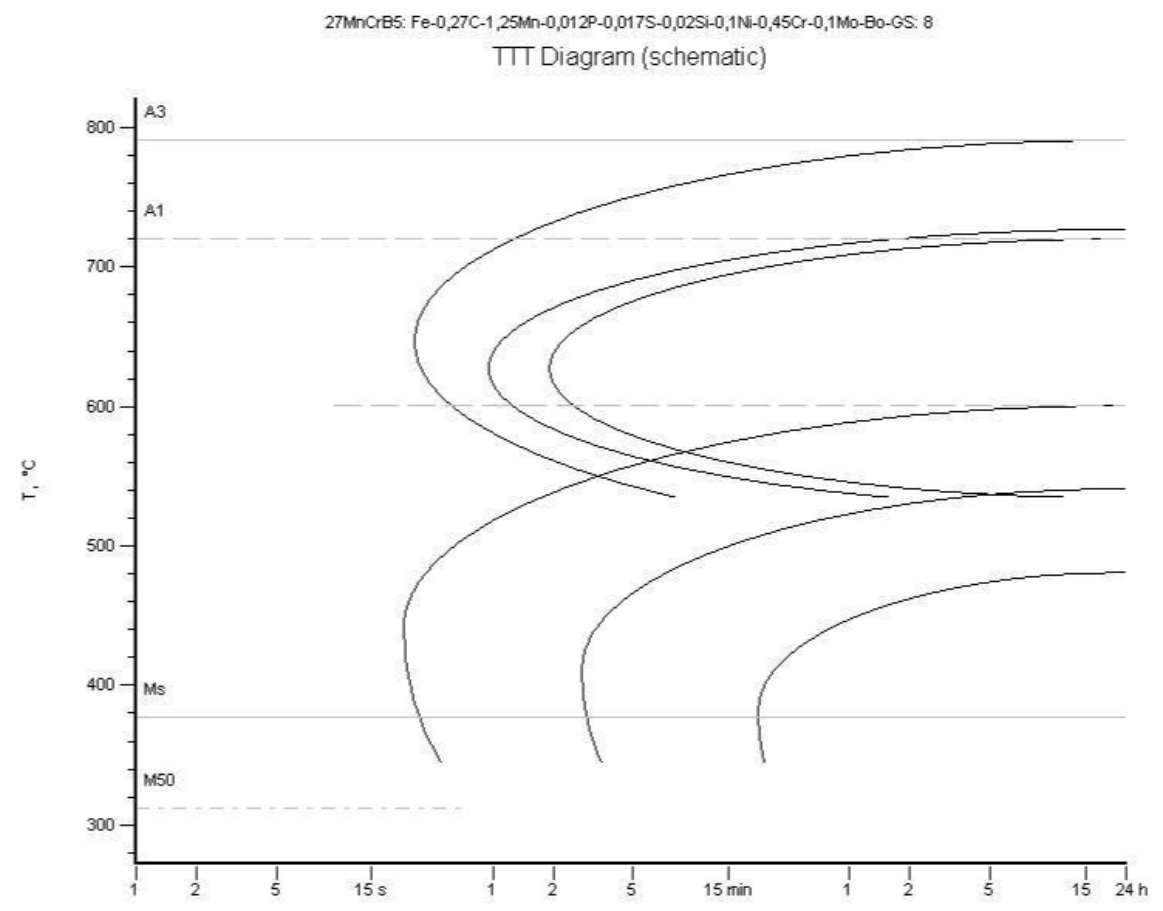

Figura 4: Curva TTT determinada pelo software Stecal 3.0.

\section{CONCEITOS DE TRATAMENTO TÉRMICO}

De acordo com Scuracchio [5] a diferença entre o processo de martêmpera e de austêmpera é a temperatura na qual o material austenitizado será resfriado. No caso da austêmpera essa temperatura é maior.

As curvas TTT com as respectivas curvas de resfriamento no processo de martêmpera e austêmpera são indicadas abaixo:
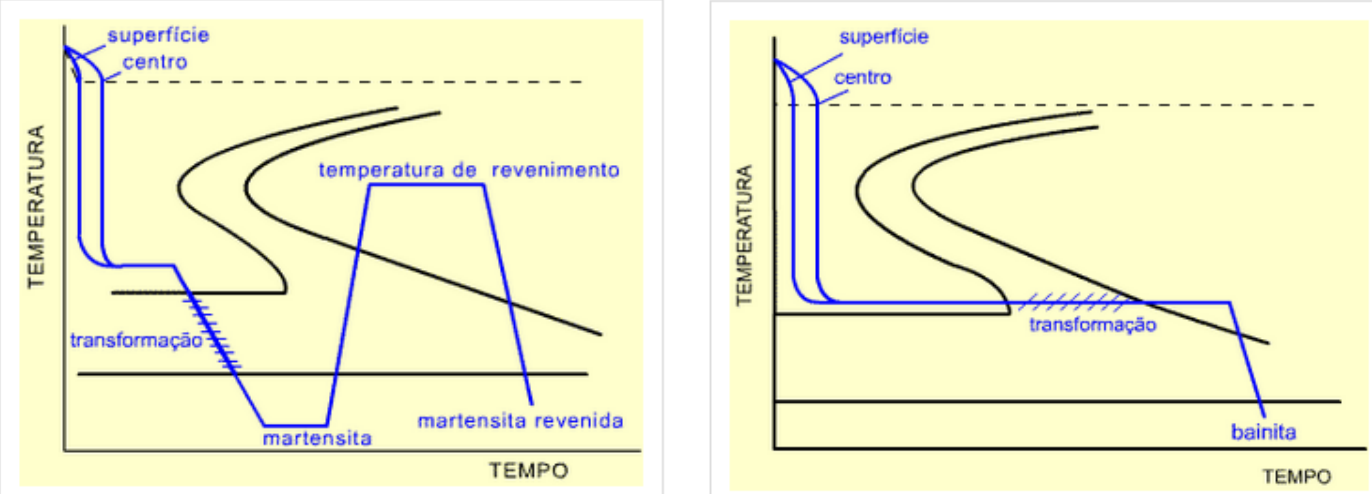

Figura 5: Curvas TTT representando processo de martêmpera (esquerda) e austêmpera (direita) [6].

Conforme site Infomet [7], quando a temperabilidade da liga é suficiente, utiliza-se um rápido estágio de homogeneização da temperatura, permitindo igualar a temperatura do centro e da superfície da peça ainda no campo austenítico. Após rápida homogeneização, prossegue-se o resfriamento para obtenção de estrutura martensítica, porém tal estrutura depende de um revenimento para diminuição da fragilidade. A este processo dá-se o nome de martêmpera. 
O processo de austêmpera consiste no resfriamento rápido até a temperatura de transformação bainítica que é mantida até a conclusão da transformação. Neste caso não há necessidade de processo subsequente de revenimento como no caso do processo de martêmpera.

\section{MATERIAIS E MÉTODOS}

\subsection{Composição Química}

A composição química foi realizada em Espectrofotômetro de Emissão Óptica e os resultados encontrados na matéria prima testada são apresentados na tabela 2.

Tabela 2: Composição química do material testado

\begin{tabular}{|c|c|c|c|c|c|c|c|}
\cline { 2 - 8 } \multicolumn{1}{c|}{ 27MnCrB5 } & $\mathbf{C ~ ( \% )}$ & $\mathbf{S i}(\%)$ & $\mathbf{M n}(\%)$ & $\mathbf{P}(\%)$ & $\mathbf{S}(\%)$ & $\mathbf{C r}(\%)$ & $\mathbf{B}(\%)$ \\
\hline
\end{tabular}

\subsection{Processo de Relaminação}

O material em estudo foi adquirido no estado laminado à quente sendo posteriormente processado conforme sequência de processos abaixo. As dimensões finais da tira são $1,42 \times 24,00 \mathrm{~mm}$.

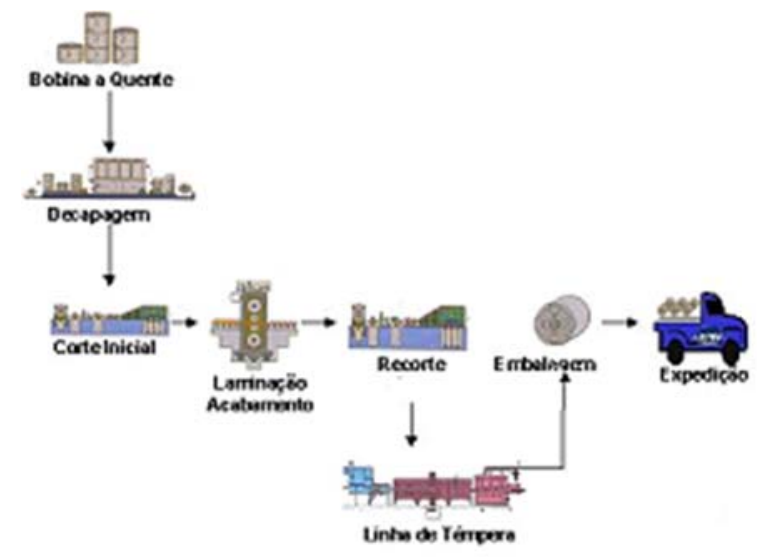

Figura 6: Fluxo de processo utilizado para o material em estudo.

\subsection{Identificação das Amostras e Parâmetros de Processo}

A tabela abaixo visa ilustrar comparativamente os parâmetros de processo para cada lote processado e relacionar os resultados dos ensaios com a respectiva amostra.

Tabela 3: Identificação das amostras e do processamento de tratamento térmico a que foram submetidas

\begin{tabular}{|c|c|c|c|c|}
\hline Amostra & Processo & Austenitização $\left({ }^{\circ} \mathrm{C}\right)$ & Resfriamento $\left({ }^{\circ} \mathrm{C}\right)$ & Revenimento $\left({ }^{\circ} \mathrm{C}\right)$ \\
\hline 1 & Martêmpera & $\uparrow \uparrow$ & $\downarrow$ & $\uparrow \uparrow$ \\
\hline 2 & Martêmpera & $\uparrow \uparrow \uparrow$ & $\downarrow$ & $\uparrow \uparrow$ \\
\hline 3 & Austêmpera & $\uparrow$ & $\uparrow$ & $* \uparrow$ \\
\hline 4 & Austêmpera & $\longrightarrow$ & $\uparrow$ & \multirow{}{*}{$\uparrow$} \\
\hline
\end{tabular}




\subsection{Propriedades Mecânicas}

As propriedades mecânicas foram obtidas conforme norma NBR 6673:1981 [8]. Foi retirado um corpo de prova paralelo ao sentido de laminação para cada parâmetro de tratamento térmico utilizado.

Os ensaios foram realizados em máquina de tração Zwick modelo Z250 equipada com garras hidráulicas e extensômetro, porém este último não foi utilizado devido risco de avaria com a ruptura das amostras durante ensaio (material frágil).

\subsection{Microscopia Óptica (Mo)}

Análise de microestrutura foi realizada nas amostras coletadas. As mesmas foram devidamente polidas e atacadas com reagente nital $3 \%$ para visualização da microestrutura no sentido de laminação, conforme ilustra a figura abaixo. Houve tentativa de ataque para avaliar tamanho de grão austenítico (reagente Picral).

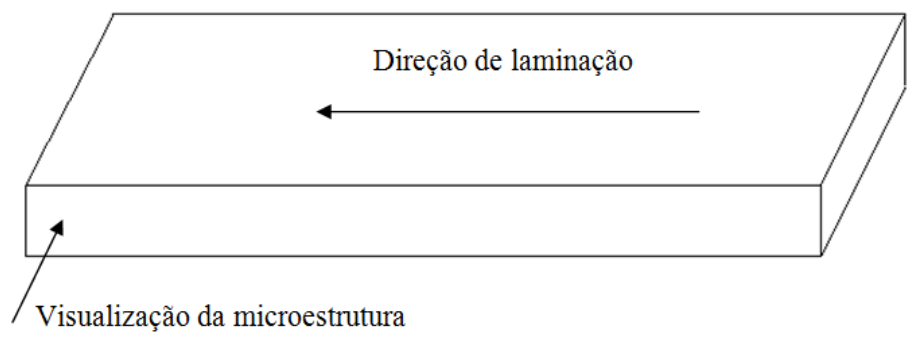

Figura 8: Ilustração da amostragem para avaliação da microestrutura.

\subsection{Teste de Conformação}

Os testes de conformação foram realizados em uma amostra para cada parâmetro de processo após o tratamento térmico, com o auxílio de dobradeira manual conforme figura abaixo:

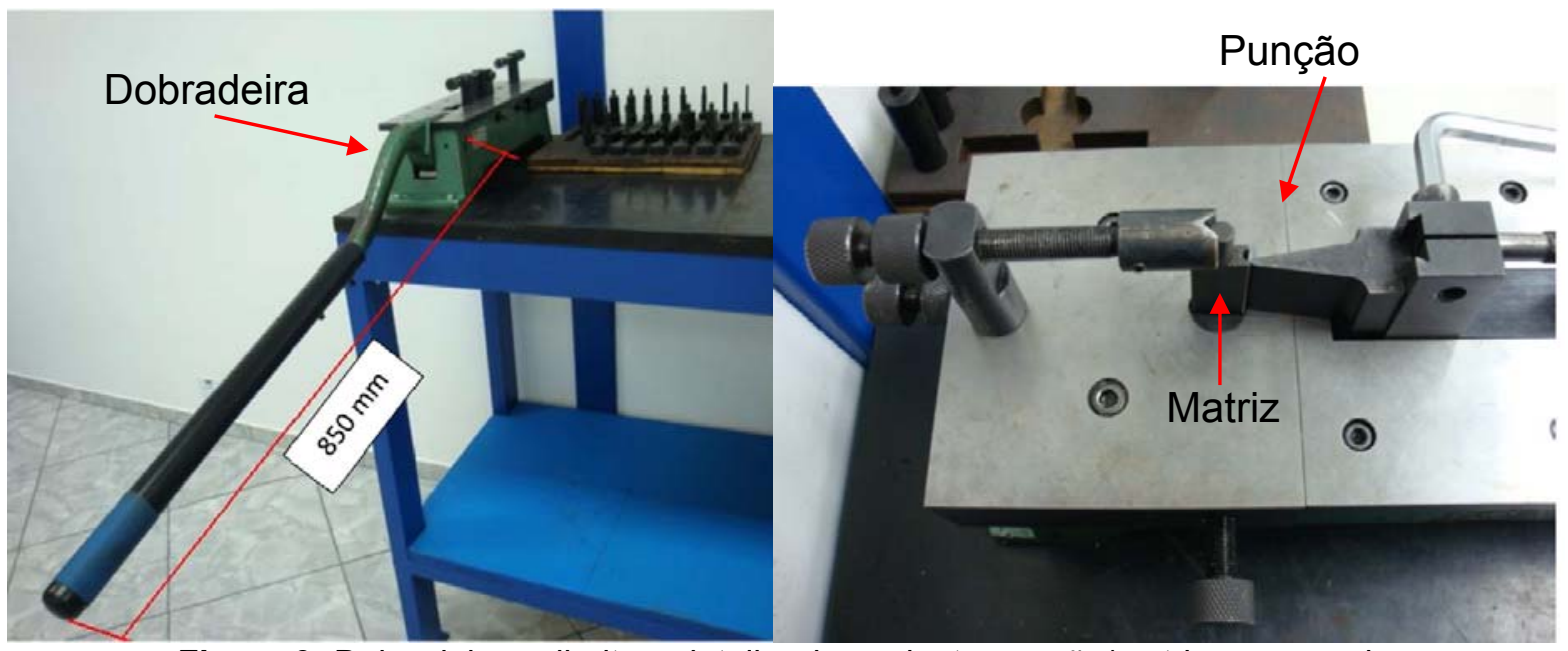

Figura 9: Dobradeira a direita e detalhe do conjunto punção/matriz a esquerda. 


\section{RESULTADOS}

\subsection{Propriedades Mecânicas}

Ensaios de tração realizados em amostras do material processado com diferentes parâmetros de tratamento térmico apresentaram os resultados conforme destacado na tabela abaixo:

Tabela 4: Propriedades mecânicas das amostras tratadas com diferentes parâmetros de têmpera

\begin{tabular}{|c|c|c|c|}
\hline Amostra & LR (MPa) & LE (MPa) & $\begin{array}{c}\text { Alongamento } \\
\text { Base A5 (\%) }\end{array}$ \\
\hline 1 & 1051 & 1042 & 4,8 \\
\hline 2 & 1045 & 1038 & 5,2 \\
\hline 3 & 1030 & 918 & 8,5 \\
\hline 4 & 1062 & 948 & 9,3 \\
\hline
\end{tabular}

\subsection{Microscopia Óptica (Mo)}

Na figura abaixo é possível verificar a microestrutura das amostras 1, 2, 3 e 4:

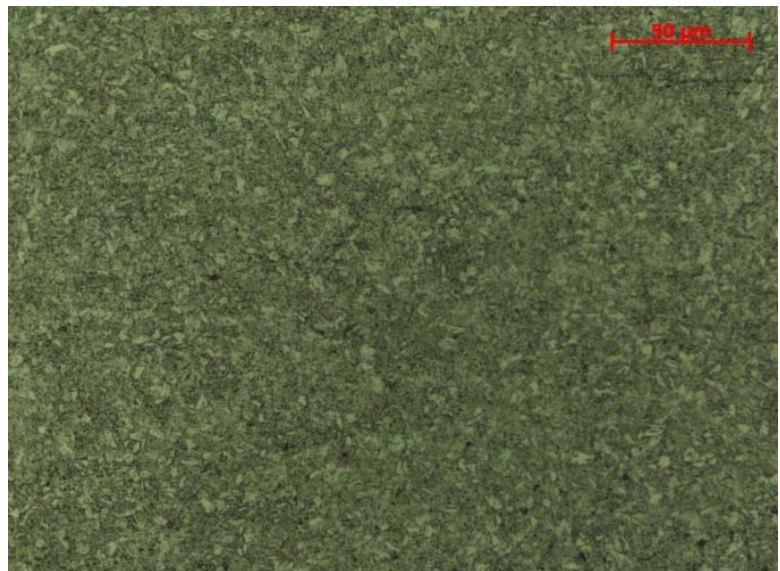

(1)

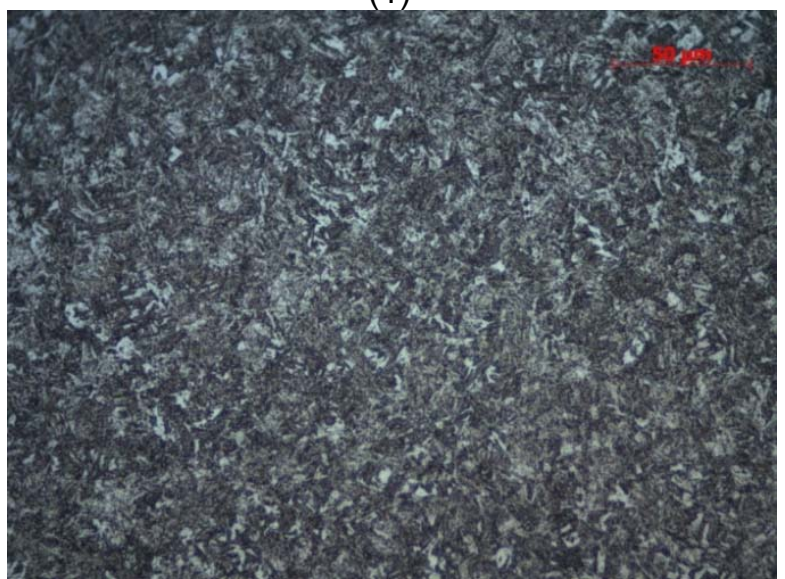

(3)

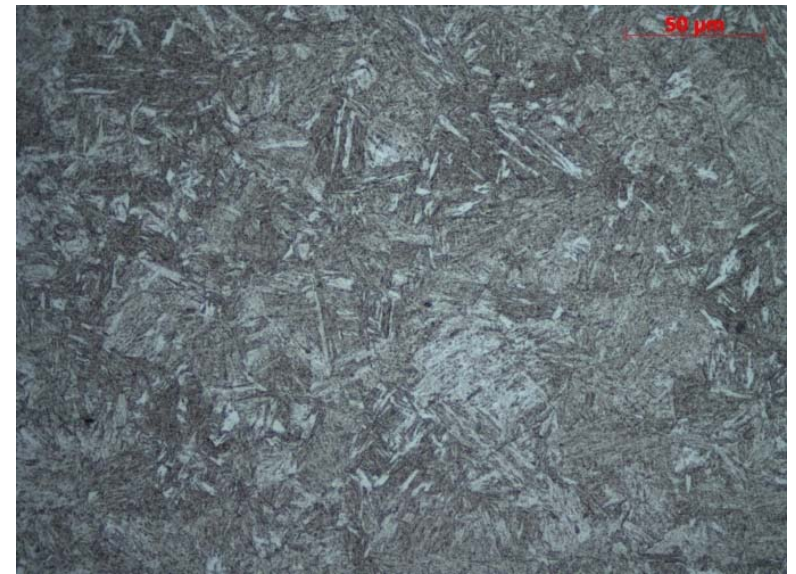

(2)

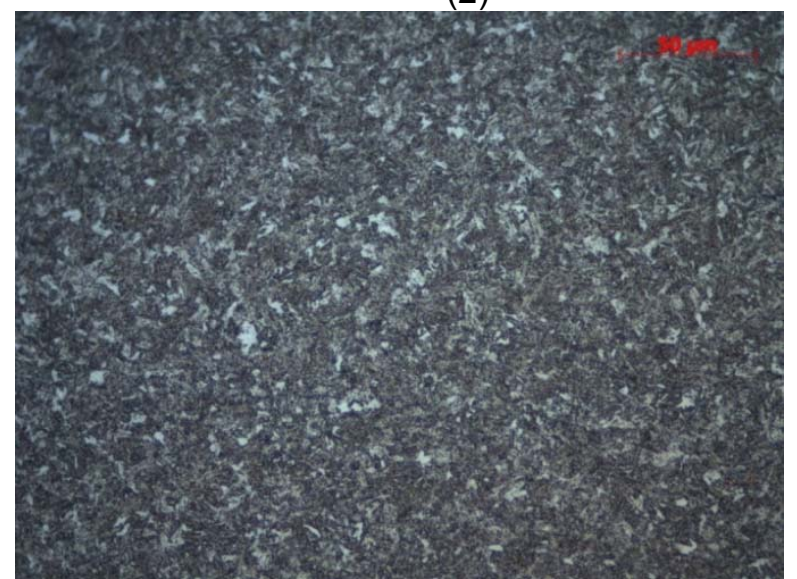

(4)

Figura 10: Microestruturas dos materiais martemperados (amostras 1 e 2) e dos materiais austemperados (amostras 3 e 4). Aumento de 500x com ataque Nital 3\%. 


\subsection{Testes de Conformação}

As amostras foram conformadas para análise visual conforme fotos (amostras 1, 2 e 3 reprovadas por apresentar trincas e amostra 4 aprovada - isenta de trincas):

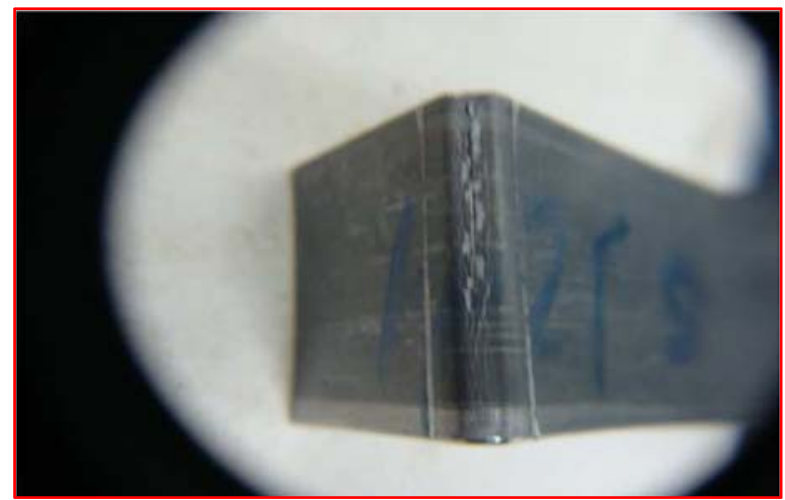

(1)

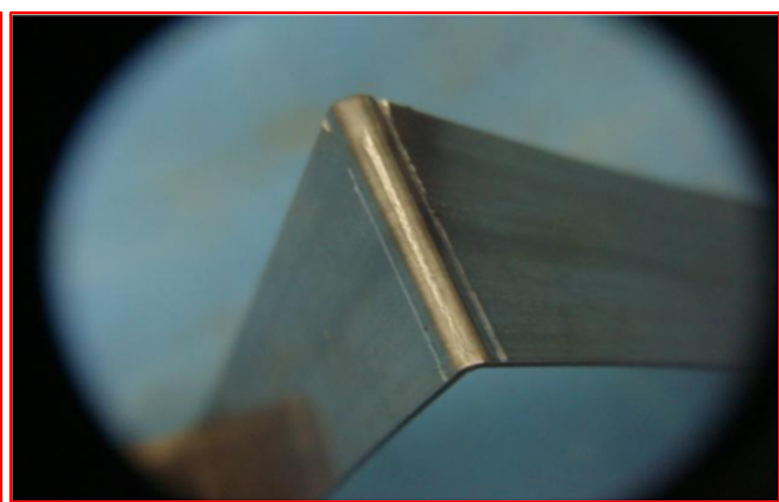

(2)

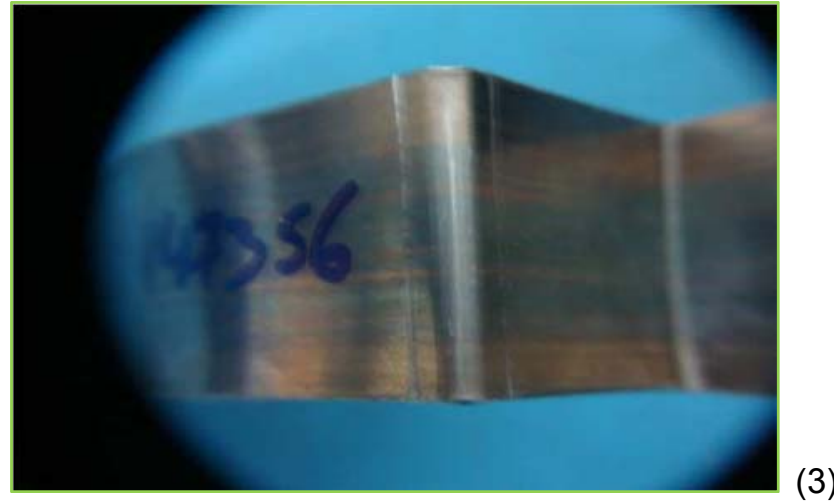

Figura 11: Resultados da análise visual do teste de dobra realizado nas amostras 1, 2 e 3 (reprovadas) e amostra 4 (aprovada).

\section{DISCUSSÃO}

\subsection{Propriedades Mecânicas}

Avaliando os resultados de propriedade mecânica é possível notar que, apesar de valores de limite de resistência muito similares, as amostras temperadas com processo de martêmpera apresentam maiores valores de limite de escoamento se comparadas com as amostras temperadas com processo de austêmpera. Outra observação importante está relacionada com o valor do alongamento encontrado, mais baixo nas amostras martemperadas se comparado com as austemperadas.

Dada a maior dutilidade da bainita é de se esperar um maior alongamento e melhor dobramento das amostras austêmperadas em comparação com as amostras martemperadas. Fato este comprovado através dos resultados de tração e avaliação visual da dobra.

\subsection{Microestrutura e Testes de Conformação}

Possível observar amostras 1 e 2 estrutura acicular típica da martensita. Na amostra 2 é possível verificar estrutura mais grosseira se comparada a amostra 1 para a mesma matéria prima utilizada. Acredita-se que a estrutura mais grosseira da amostra 2 seja devido a elevada temperatura de austenitização em comparação a amostra 1 
(recomendado de acordo com a curva TTT dessa liga em torno de $850^{\circ} \mathrm{C}$, aproximadamente $50^{\circ} \mathrm{C}$ acima de $A_{3}$ ). Elevada temperatura de austenitização promove o crescimento de grão austenítico devido dissolução de carbono na austenita, removendo as barreiras que impedem o crescimento de grão austenítico em elevadas temperaturas. Não foi possível comparar o tamanho de grão austenítico das amostras pois o reagente utilizado (Picral) não revelou o contorno de grão austenítico do aço 27MnCrB5-2.

As amostras 3 e 4 não apresentam estrutura acicular, dessa forma afirma-se a presença de bainita onde verifica-se na amostra 3 uma estrutura mais grosseira e menor alongamento se comparada a amostra 4, fato que pode explicar a trinca na amostra 3 devido menor caminho para propagação da mesma.

$\mathrm{Na}$ comparação das amostras conformadas no teste de dobramento é possível verificar que as amostras martemperadas foram reprovadas, independente da estrutura mais fina ou mais grosseira. Quanto as amostras austemperadas é possível observar visualmente melhora na dobra se comparadas com as amostras martemperadas. Entretanto a amostra austemperada com estrutura mais grosseira (amostra 3) apresentou ruptura no teste de dobra ao passo que a amostra com estrutura mais fina (amostra 4) não apresentou ruptura no mesmo teste, pelo mesmo motivo explicado no parágrafo anterior.

\section{CONCLUSÕES}

Através dos testes conduzidos foi possível concluir:

- A temperatura de austenitização mais alta aplicada durante processo de martêmpera (amostra 2) acarretou em estrutura martensítica grosseira e influenciou negativamente no teste de dobra e na produção da faca, provocando a ruptura da tira;

- A temperatura de austenitização mais baixa aplicada durante processo de martêmpera (amostra 1) acarretou em estrutura martensítica fina. A tira conformada no teste de dobra apresentou trincas na mesma proporção verificada na amostra 2 , sendo ambas as amostras reprovadas no teste através de análise visual e na fabricação da faca, inabilitando dessa forma o processo de martempera para essa aplicação;

- As amostras 3 e 4 austemperadas apresentaram os maiores alongamentos nos testes de tração e estrutura bainítica, sendo mais recomendadas para a aplicação facas de corte e vinco devido a maior dutilidade da estrutura bainítica em comparação a estrutura martensítica;

- Possível observar estrutura mais fina e alongamento maior na amostra 4 se comparada com a amostra 3. Essa diferença foi suficiente para inabilitar os parâmetros de processo empregados na amostra 3 pois houveram trincas na amostra durante teste de dobra e durante fabricação da faca;

- Com o processo de austêmpera empregado na amostra 4 foi possível atender o requisito de dobra bem como as criticidades de conformação da aplicação final.

\section{Agradecimentos}

Os autores agradecem a empresa Brasmetal Waelzholz, por ter cedido os equipamentos e mão de obra que tornaram possível a desenvolvimento e conclusão do projeto realizado e ao Sr. André Sereno Lopes por incentivar seu desenvolvimento. 


\section{REFERÊNCIAS}

1 Acesso em 03/04/15; Disponível em "http://inter.brasmetal.com.br/sys/download/BaixaLiga.pdf";

2 Acesso em 05/04/15; Disponível em "http://www.inda.org.br/aco_liga.php";

3 Acesso em 06/04/15; Disponível em "http://www.ailtonfacas.com.br/site/servicos/Facasde-corte-e-vinco";

4 Norma DIN EN 10083-3: 2006;

5 Scuracchio, B. G.. et. al. "Austêmpera de Tiras de Aço Carbono em Forno Contínuo" Acesso em 01/04/15. Disponível em "http://www.outraspalavras.org/maffeis/wpcontent/uploads/2012/02/AUST\%C3\%8AMPERA-DE-TIRAS-DE-A\%C3\%87OCARBONO-EM-FORNO-CONT\%C3\%8DNUO.pdf"

6 Acesso em 01/04/15. Disponível em "http://www.cimm.com.br/portal/material_didatico/6443-principios-tratamento-detempera-e-suas-variacoes-tempera-austempera-martempera\#.VSe-BdzF-So"

7 Acesso em 01/04/15. Disponível em "http://www.infomet.com.br/site/acos-e-ligasconteudo-ler.php?codConteudo=221";

8 Norma NBR 6673:1981. 